\title{
Caracterización Hídrica de la Cuenca del Arroyo Vaquerías (Córdoba, Argentina) Mediante el Modelado Hidrológico e Información Satelital
}

\section{Hydric characterization of the Vaquerías watershed (Córdoba, Argentina) throught hydrological modeling and satellite information}

Presentación: 27/08/2020

Aprobación: 09/10/2020

\section{Juan Weber}

Laboratorio de Hidráulica, Facultad Córdoba, Universidad Tecnológica Nacional - Argentina Departamento de Computación, Facultad de Ciencias Exactas, Físicas y Naturales, Universidad Nacional de Córdoba - Argentina

jweber@frc.utn.edu.ar

\section{Resumen}

Se presenta una caracterización hidrológica, mediante el modelado computacional, de la cuenca del arroyo Vaquerías. Esta cuenca, carente de cualquier sistema de monitoreo, representa la principal fuente del recurso hídrico de la Reserva Natural Vaquerías, perteneciente a la Universidad Nacional de Córdoba. Como fuente de información para la precipitación se recurrió al producto CHIRPS (Climate Hazards group InfraRed Precipitation with Station data), y para la evapotranspiración, al producto MOD16A2. Los datos fueron procesados en la plataforma Google Earth Engine. El modelado se realizó a través del modelo semidistribuido TOPMODEL, que en forma simplificada considera la contribución al escurrimiento de los flujos superficial y subterráneo. A pesar de las limitaciones de la información de entrada como del modelo implementado, y en el contexto de la ausencia de información de campo, fue posible caracterizar hidrológicamente la cuenca en estudio.

Palabras claves: Reserva Natural Vaquerías, TOPMODEL, CHIRPS, Google Earth Engine

\begin{abstract}
A hydrological characterization is presented, through computational modeling, of the Vaquerías watershed basin. This basin, lacking any monitoring system, represents the main source of water of the Vaquerías Natural Reserve (National University of Córdoba. CHIRPS
\end{abstract}


(Climate Hazards group InfraRed Precipitation with Station data) was used as precipitation source data; MOD16A2 was used as evapotranspiration source data. Data was processed through Google Earth Engine platform. The modeling was carried out through the TOPMODEL semi-distributed model, which in a simplified way considers the contribution of superficial and groundwater flows to the runoff. Despite the limitations of the input information and the implemented model, and in lack of field information, it was possible to carry out a hydrological characterization of studied watershed.

Keywords: Vaquerías Natural Reserve, TOPMODEL, CHIRPS, Google Earth Engine

\section{Introducción}

\section{Generalidades}

La cuenca del arroyo Vaquerías se ubica sobre el faldeo occidental de las Sierras Chicas, en el Valle de Punilla, provincia de Córdoba, Argentina. Representa la mayor fuente del recurso hídrico para la Reserva Natural de Vaquerías (Figura 1).

La Reserva Natural de Vaquerías (RNV) fue creada mediante Resolución Rectoral $\mathrm{N}^{\circ}$ 1780/90 de la Universidad Nacional de Córdoba (UNC); posteriormente, por Ley provincial $N^{\circ}$ 8.081, se constituyó como Reserva Provincial de Uso Múltiple (Ley Nº 6.964/83 de Áreas Naturales) de la Provincia de Córdoba. El status legal del área protegida es el de un espacio natural de dominio privado de la Universidad Nacional de Córdoba (UNC), que se encuentra bajo régimen de protección y restricción legal provincial específico.

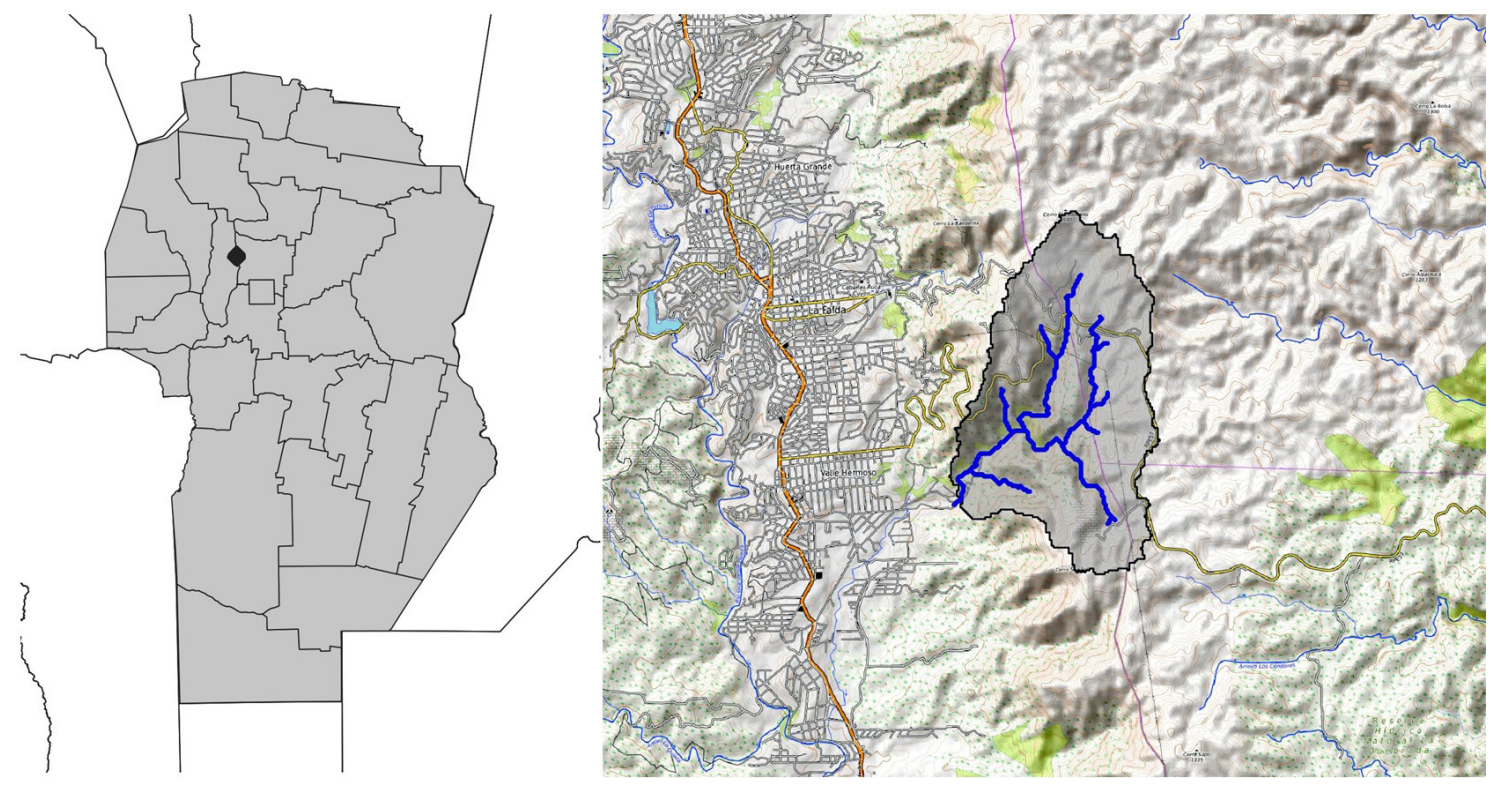

Fig. 1. Ubicación de la cuenca del Arroyo Vaquerías

La RNV pertenece a la UNC y su Complejo Turístico se encuentra bajo usufructo temporario de la DASPU (Dirección de Asuntos Sociales del Personal Universitario); sin embargo 
desde sus orígenes ha existido confusión sobre su situación. Ello, sumado a la pasividad de la UNC respecto de la reserva, ha colaborado a su condición actual de degradación general (Kufner, 2012).

Por sus particulares características, la belleza de sus paisajes y abundancia de recursos, Vaquerías fue apreciada tanto por las poblaciones originarias que habitaron este territorio al que llamaron - Lampatu Mayu - durante los siglos XV y XVI, como los españoles a partir de la colonización en el siglo XVIII.

Su nombre actual se debe a que los jesuitas destinaron este sitio para la cría de ganado vacuno, siendo además un lugar de paso por el antiguo camino real. Alrededor del año 1900, los predios de Vaquerías fueron adquiridos por el Sr. Antonio Marcuzzi, que inicia la construcción de un complejo hotelero en este privilegiado lugar, rodeado de sierras y circundado por un caudaloso arroyo. Finalmente en el año 1970, la Universidad Nacional de Córdoba compra las 400 hectáreas que componen hoy el complejo turístico y el área de la reserva.

El correcto funcionamiento de la Reserva Natural Vaquerías es una de las prioridades de la Universidad Nacional de Córdoba. En el año 2009 se elaboró el Plan de Manejo de la Reserva Natural Vaquerías, en el año 2010 el Plan de Manejo es aprobado por el Honorable Consejo Superior de la Universidad y en 2011 se asignaron fondos para el desarrollo de acciones prioritarias de conservación en la Reserva, entre otras cosas, la contratación de los Guardaparques. Es así que actualmente la Universidad Nacional de Córdoba se encuentra con el desafío de revertir los impacto ambientales generados sobre la Reserva y su zona de influencia, tales como: invasión de especies exóticas, retracción de bosque nativo, incendios, construcción de caminos con derrumbes y erosión de suelos, restauración de sitio degradado por explotación minera, incremento de la afluencia de visitantes, entre otros.

La Reserva Natural Vaquerías es uno de los últimos relictos del ecosistema serrano en la región norte del Valle de Punilla. Esta área natural representa un valor natural incalculable desde lo ambiental, lo ecológico, lo geomorfológico y como plataforma para realizar estudios de diversa índole.

\section{Caracterización climática}

La zona de Vaquerías se encuentra climáticamente condicionada a diferentes escalas por la relación entre las formas del terreno y su ubicación relativa. La condición rectora es la altura y rumbo de las sierras, siguiéndole en importancia el rumbo y la pendiente de las laderas de las quebradas. (Abril y Zanvettor, 2012).

Según la clasificación de Thornwaite, el clima de la región corresponde al tipo C1B2'da', es decir, sub-húmedo seco, mesotérmico templado cálido, con nulo exceso de agua y con baja concentración de la eficiencia térmica. Según Köppen, en tanto, el clima es un tipo Cwa, esto es, un clima templado húmedo con estación invernal seca y con verano caluroso.

No obstante, se habla de que la zona posee un microclima, un clima local con características diferentes a las de la zona en que se encuentra. Esto podría deberse a las características particulares de su topografía, temperatura, humedad, altitud-latitud, luz y cobertura vegetal (Abril y Zanvettor, 2012)

\section{Caracterización geológica y edafológica}

El área central de la Sierra Chica está representada por afloramientos paleozoicos, intrusiones graníticas menores y sedimentos meso-cenozoicos. El basamento (paleozoico) está compuesto por gneises, esquistos tonalíticos-biotíticos, cuarcitas micáceas, anfibolitas, mármoles y filitas. 
La zona es particularmente rica en elementos relacionados con la tectónica regional. La principal estructura es la falla de Punilla: se trata de la fractura que define el pie occidental de la Sierra Chica, conformando una rampa tectónica con un rumbo casi meridiano y un buzamiento entre $50^{\circ}-60^{\circ}$ al Este. Esta falla da lugar a una serie de escalones tectónicos a través de los cuales se produjo el ascenso gradual del basamento, en el pie occidental de la Sierra Chica.

La intensa deformación y ruptura a la que fueron sometidas las diferentes unidades litológicas de la comarca, han sido definitorias de la geomorfología actual. El área comprende los cinco ambientes geomorfológicos clásicos de una zona marginal de falla a saber, las cumbres, los flancos, las quebradas, el pedemonte y el valle (Abril, 2012).

Los suelos de la zona presentan perfiles poco desarrollados, formados por una sucesión de capas con textura franco arenosa a arenosa franca, con altos contenidos de gravilla. En cuanto a sus características químicas, los suelos en general son ácidos, manifestando en algunos casos una leve alcalinidad por presencia de carbonato de calcio diseminado. Taxonómicamente, los suelos se clasifican como Ustorthentes típicos o paralíticos. Los perfiles en la Ladera Sur están más desarrollados que los de la ladera Norte; mientras que estos últimos contienen mayores porcentajes de arcillas y limos (Cejas y Sacchi, 2012).

\section{Caracterización de la cobertura vegetal}

La RNV protege un marco típico de Bosque Serrano mejor conservado en la parte alta. En las zonas bajas, entre los 850 y $900 \mathrm{msnm}$, así como en las proximidades de las viviendas, el bosque está degradado y sujeto a presión de hábitat por especies introducidas de árboles y arbustos (Figura 2). El bosque serrano presenta variaciones de acuerdo con la exposición de las laderas: la exposición solar es mayor en las laderas Sur y menor en las laderas Norte.

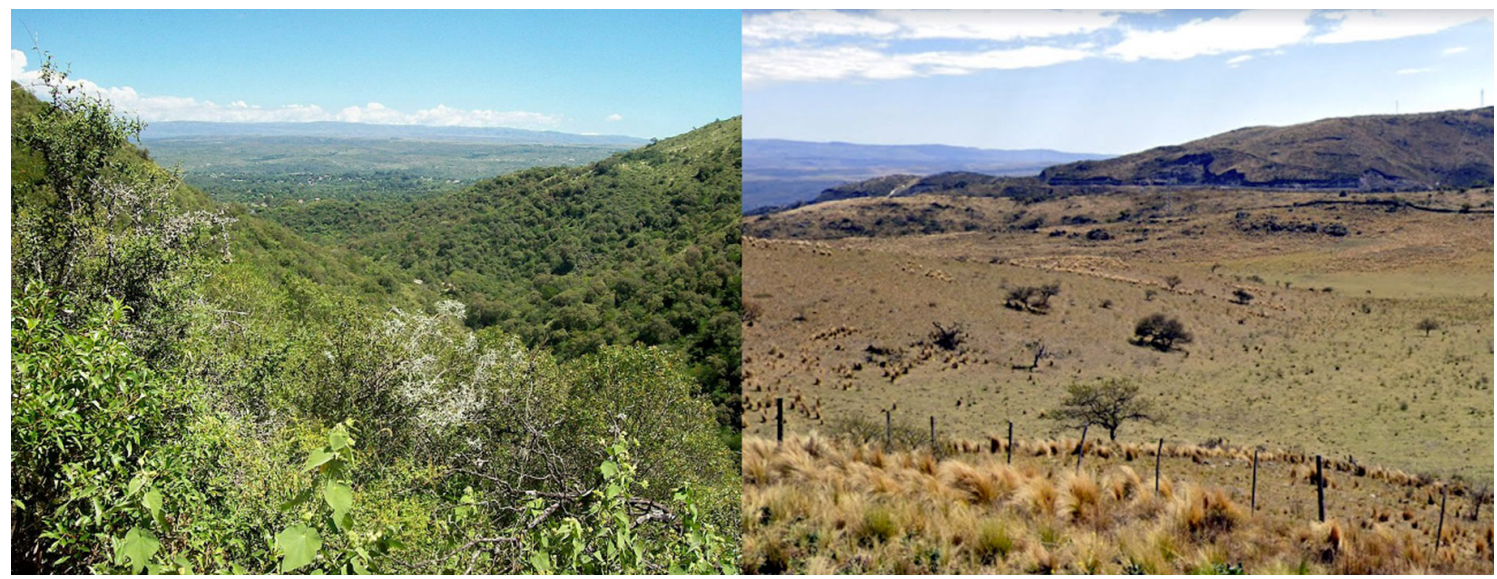

Fig. 2. Cobertura vegetal de la cuenca de Vaquerías: bosque serrano (izq.) y pastizales de altura (der.). Fuente: https://es.wikipedia.org/wiki/Vaquerías

Las especies típicas: molle, manzano del campo, piquillín de las sierras y coco, se encuentran en lugares alejados de las viviendas y de los cursos de agua. En los bordes altos de arroyos se destaca la presencia de diversas especies de helechos, como doradillas y culantrillos. Superando los 1100 msnm, el Bosque Serrano comienza a hacerse más ralo, dejando paso a 
un arbustal misto formado por Baccharis, Acacia, chilcas, romerillos y Colletia. Más arriba, se halla un estrato bajo de vegetación, formado por pastizales de Poa y Nassella, arbustos y árboles muy aislados (Toledo y Nóbile, 2012).

\section{Caracterización hidrográfica}

La cuenca bajo análisis pertenece a la cuenca del río Cosquín, tributario del Lago San Roque y por tanto del río Suquía o Primero. El área es de 12,3 $\mathrm{km}^{2}$, lo que representa sólo el 2,5\% de la superficie de la cuenca del Cosquín (Figura 3).

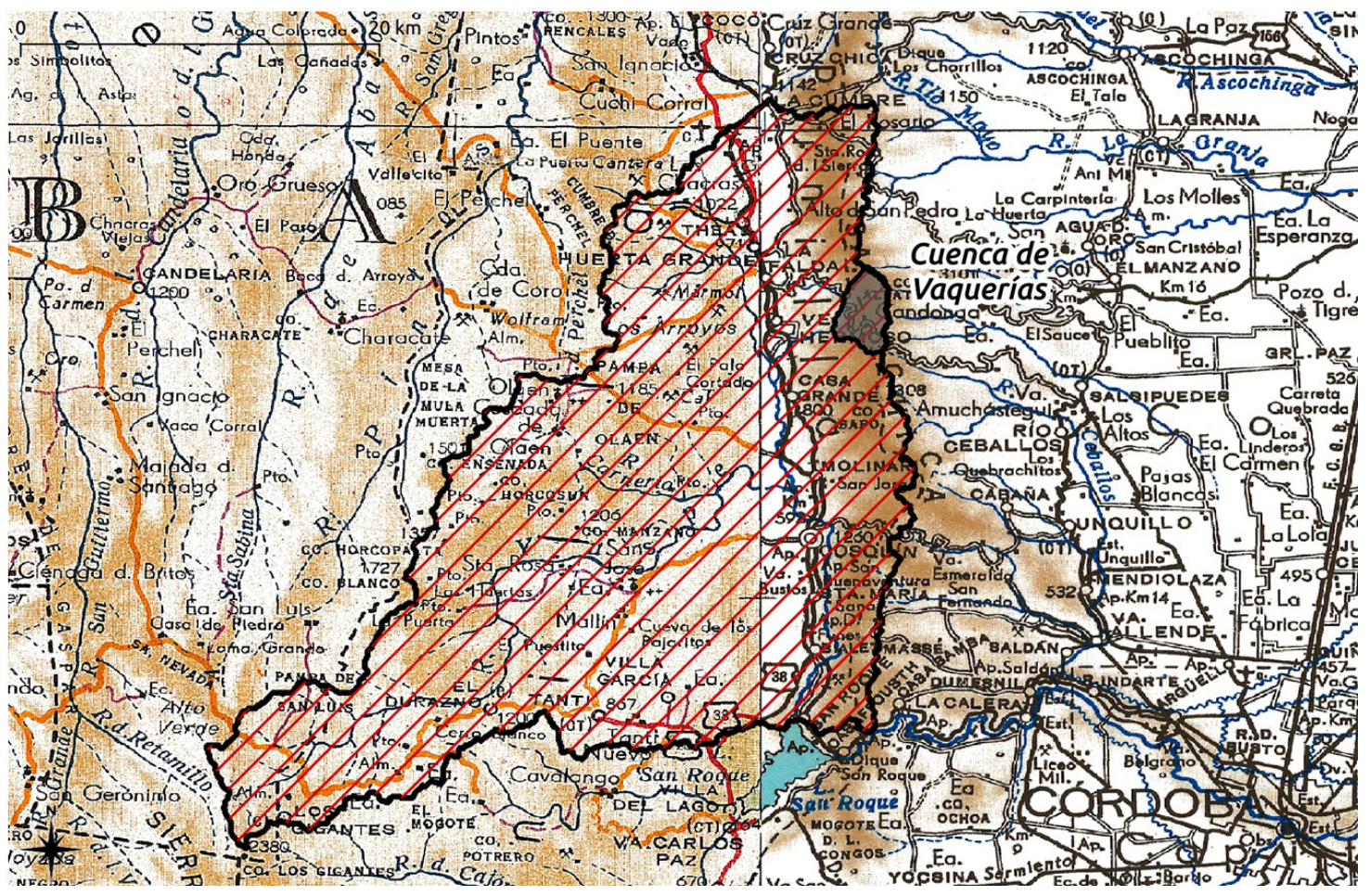

Fig. 3. Ubicación de la cuenca de Vaquerías en la cuenca del río Cosquín. Mapa base: Carta 1:500.000 IGN

Su perímetro es del orden de 17,6 km, lo cual da lugar a un coeficiente de Gravelius de 1,40. La red de drenaje es del tipo dendrítica, según se observa en la Figura 4. El cauce principal (arroyo Vaquerías) tiene una longitud de 6,4 km, salvando un desnivel total de $580 \mathrm{~m}$ aproximadamente, lo que da una pendiente media del cauce del $9 \%$. La altitud media de la cuenca es de 1246 m.s.n.m. La cuenca puede ser subdividida en 4 subcuencas, de características hidrológicas similares, según se indica en la Figura 4. El área de cada subcuenca, como la longitud y pendiente de su cauce principal figuran en la Tabla 1 (Weber, 2012). 


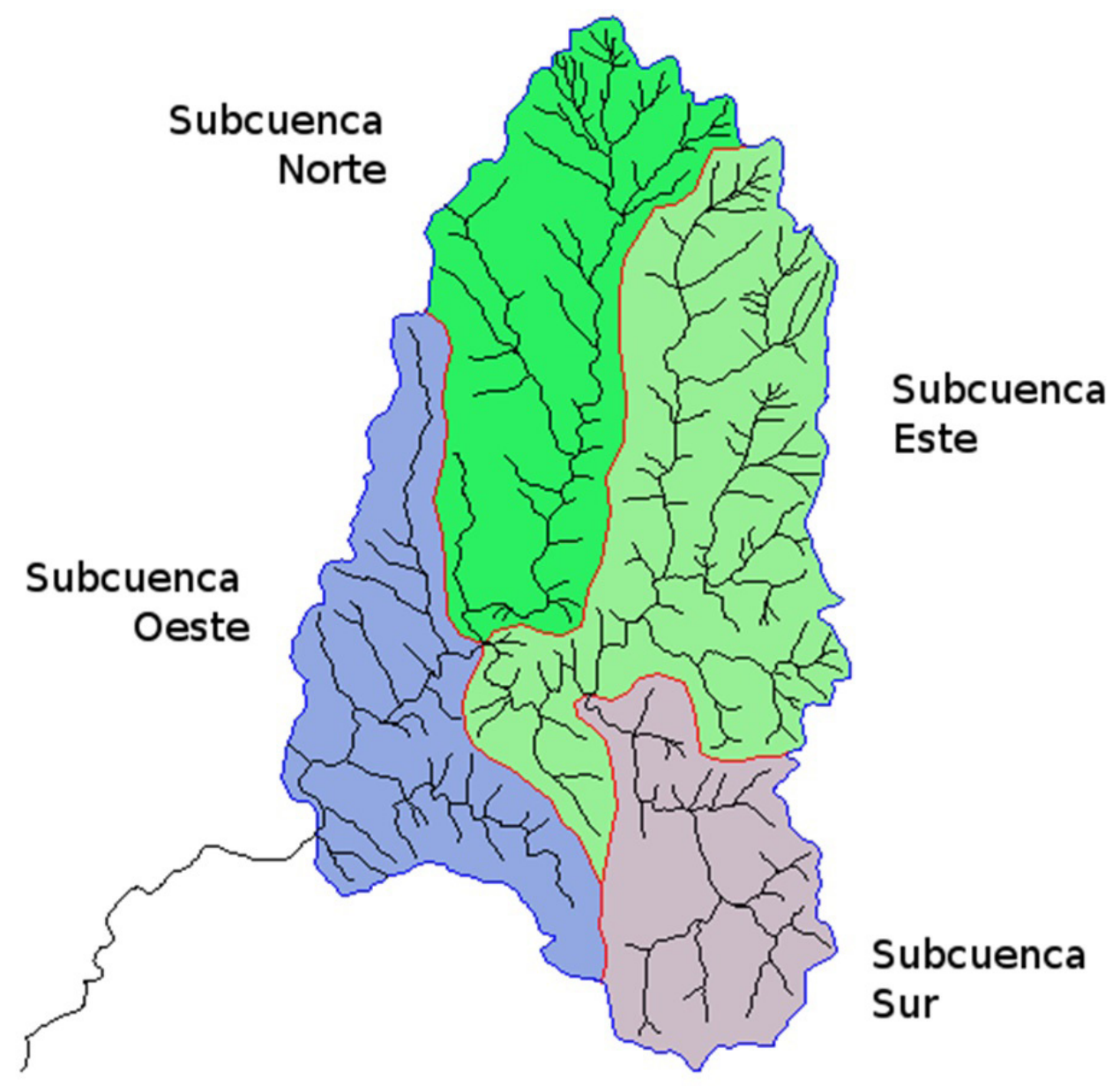

Fig. 4. Cuenca del Arroyo Vaquerías y Subcuencas consideradas (Weber. 2012)

\begin{tabular}{|c|c|c|c|}
\hline Subcuenca & Area $\left(\mathrm{km}^{2}\right)$ & Long. Cauce $(\mathrm{km})$ & Pendiente $(\%)$ \\
\hline Norte & 3,4 & 4,3 & 6,3 \\
\hline Sur & 4,2 & 2,5 & 8,9 \\
\hline Este & 2,0 & 5,1 & 8,4 \\
\hline Oeste & 2,7 & 2,2 & 5,1 \\
\hline
\end{tabular}

Tabla 1. Características de las subcuencas del Arroyo Vaquerías

\section{Desarrollo}

\section{Información topográfica}

Para la caracterización topográfica del área de estudio se utilizó un Modelo Digital de Elevaciones (MDE) generado a partir de la información de la Shuttle Radar Topography Mission (SRTM) (Farr et al., 2007). Los datos de elevación digital de la SRTM son el producto de un esfuerzo de investigación internacional que obtuvo modelos de elevación digital en 
una escala casi global. El producto aquí utilizado, SRTM V3 (SRTM Plus) es provisto por NASA JPL a una resolución de 1 segundo de arco (aproximadamente $30 \mathrm{~m}$ ). Este conjunto de datos se ha sometido a un proceso de llenado de vacíos utilizando datos de código abierto (ASTER GDEM2, GMTED2010 y NED), a diferencia de otras versiones que contienen vacíos o que se han llenado con fuentes comerciales.

Los errores altitudinales medios reportados para el SRTM en Sud América se distribuyen en una media de $1,7 \mathrm{~m}$, con un error absoluto de $90 \%$ de confidencia de 6,5 $\mathrm{m}$ (Rodríguez et al., 2006) lo que resulta en una exactitud y precisión adecuada para el objeto de estudio del presente trabajo.

La información original del SRTM fue reproyectada al sistema de coordenadas UTM Zona $20 \mathrm{~S}$ y recortada al área de interés mediante el Sistema de Información Geográfica QGIS (QGIS, 2020). Luego fue importada y visualizada a través del Sistema de Información Geográfica SAGA-GIS (Conrad et al., 2015).

En la Figura 5 puede verse un mapa topográfico generado a partir del Modelo Digital de Elevaciones, para la cuenca de Vaquerías.

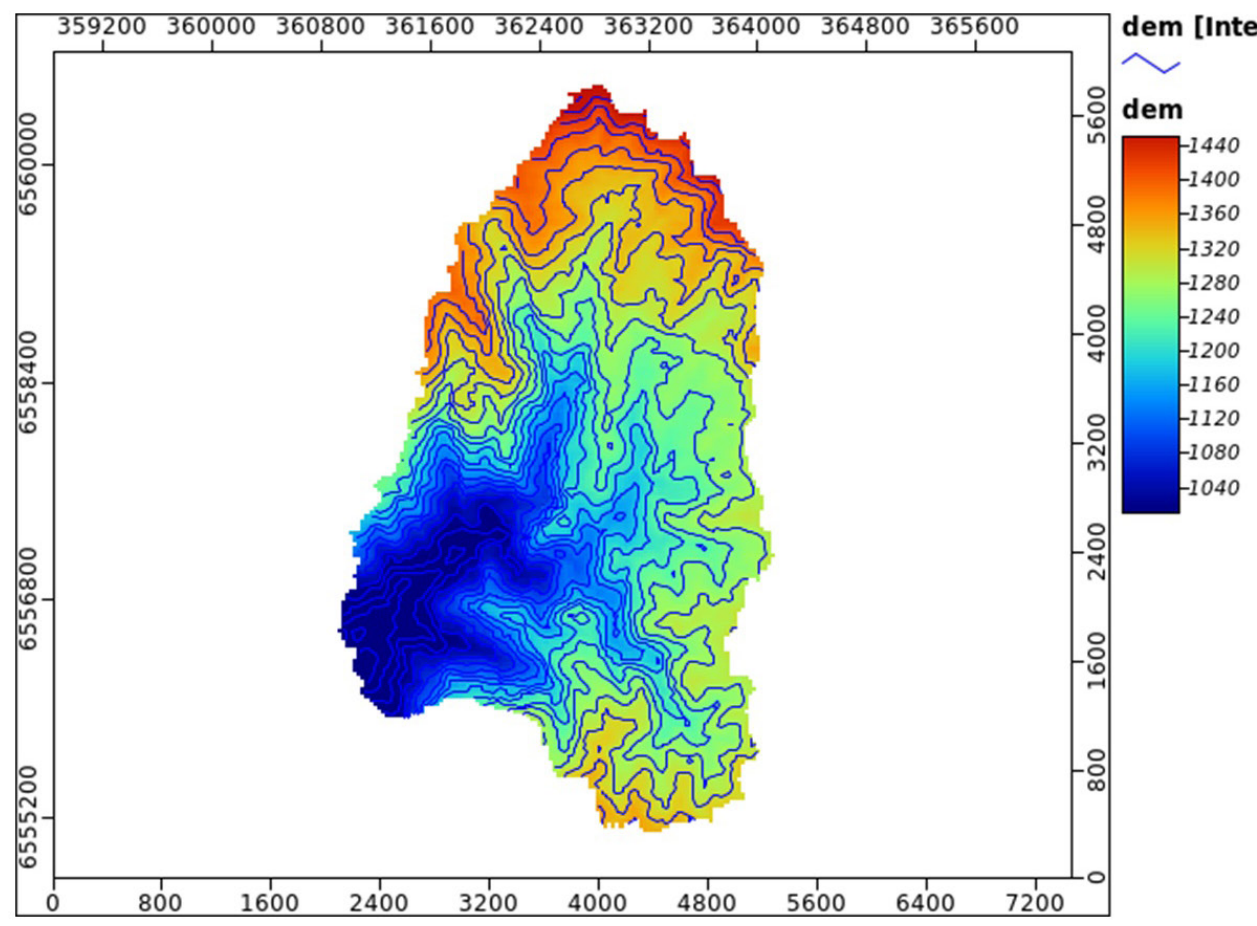

Fig. 5. Modelo Digital de Elevación de la cuenca de Vaquerías

\section{Información hidroclimática}

En ausencia de información hidroclimática local (Weber, 2012) se recurrió a información sintética disponible a partir de productos satelitales. En particular, para el trabajo realizado resulta crucial disponer de series de precipitación (P) y evapotranspiración potencial (ETP).

La precipitación fue estimada a partir de Datos de Precipitación Derivados de Satélites (DPDS). En particular, se recurrió a la información proveniente del producto CHIRPS (Funk et al., 2015). La estimación de la evapotranspiración potencial (ETP) se obtuvo a partir de la 
información del producto MOD16A2 (Mu et al., 2014).

Por la naturaleza del modelo de simulación hidrológica aplicado, a partir de estos productos hidroclimáticos espacialmente distribuidos fue necesario generar sendas series de tiempo de valores medios a nivel de cuenca. Este proceso se realizó mediante el desarrollo de un código ad-hoc en la API Code Editor de la plataforma Google Earth Engine (Gorelick et al., 2017). Earth Engine es una plataforma para el análisis científico y la visualización de conjuntos de datos geoespaciales, para usuarios académicos, sin fines de lucro, empresariales y gubernamentales. Earth Engine aloja imágenes satelitales y las almacena en un archivo de datos públicos que incluye imágenes históricas de la Tierra que datan de más de cuarenta años. Las imágenes, adquiridas diariamente, se ponen a disposición para la minería de datos a escala global (data mining). Earth Engine también proporciona una interfaz de programación de aplicaciones (del inglés API: Application Programming Interface) y otras herramientas para permitir el análisis de grandes conjuntos de datos.

Tanto para la precipitación como para la evapotranspiración, se consideró el periodo comprendido entre el 1/6/2000 y el 31/5/2011, es decir, 11 años hidrológicos.

\section{Precipitación}

Climate Hazards Group InfraRed Precipitation with Station data (CHIRPS) es un conjunto de datos de precipitaciones cuasi global de más de 30 años de cobertura temporal continua. CHIRPS incorpora imágenes satelitales de resolución de $0.05^{\circ}$ (aproximadamente, $5,4 \mathrm{~km}$ ) con datos de estaciones in situ (reanálisis) para crear series de tiempo de lluvia grilladas (ráster). El producto utilizado tiene una resolución temporal de 1 día, con una disponibilidad continua desde el 1/1/1981. Los datos son provistos por el Climate Hazards Center, University of California, Santa Barbara (USA).

CHIRPS fue desarrollado para apoyar a la Agencia de los Estados Unidos para el Desarrollo Internacional de la Red de Sistemas de Alerta Temprana (FEWS NET). Aprovechando los enfoques utilizados en productos exitosos de precipitación por infrarrojos térmicos (TIR) como la Estimación de precipitaciones (RFE2) de la Administración Nacional Oceánica y Atmosférica (NOAA) y la Rainat Climatology de África o la serie TAMSAT African Rainfall Climatology and Time de la Universidad de Reading (TARCAT). CHIRPS utiliza el Análisis de Precipitación Multisatélite de la Misión de Medición de Lluvias Tropicales, versión 7 (TMPA 3B42 v7) para calibrar las estimaciones globales de lluvia de la Duración de Nube Fría (CCD).

Además de los enfoques utilizados en los mejores interpoladores actuales, CHIRPS utiliza un enfoque de "interpolación inteligente", trabajando con las anomalías de la climatología de alta resolución. CHIRPS incorpora datos de las estaciones en un proceso de dos fases, produciendo dos productos únicos.

En la primera fase, que produce un producto de lluvia preliminar con una latencia de 2 días, los registros dispersos del Sistema Global de Telecomunicaciones (GTS) de la Organización Meteorológica Mundial se combinan con estimaciones de lluvia derivadas de CCD en cada periodo de cinco días (pentad). Hay seis pentads en un mes calendario, cinco pentads de 5 días y un pentad con los 3 a 6 días restantes del mes. En la segunda fase, que produce un producto final con una latencia de aproximadamente 3 semanas, los mejores datos de estaciones mensuales disponibles se combinan con estimaciones mensuales de precipitaciones basadas en CCD de alta resolución para producir campos raster (Funk et al., 2015). En la Figura 6 se muestra un esquema del proceso de producción de CHIRPS. 


\section{Evapotranspiración}

La estimación de la evapotranspiración potencial (ETP) se obtuvo a partir de la información del producto MOD16A2 (Mu et al., 2014). El producto MOD16A2 V105 proporciona información sobre la evapotranspiración terrestre global, con una resolución temporal de 8 días (con periodos más cortos de 6 o 5 días al final del año calendario, según se trate de años bisiestos o no, respectivamente) a una resolución espacial de $1 \mathrm{~km}$. El producto MOD16A2 es producido por el Numerical Terradynamic Simulation Group (NTSG), Universidad de Montana (UMT) en conjunto con el Sistema de Observación de la Tierra de la NASA.

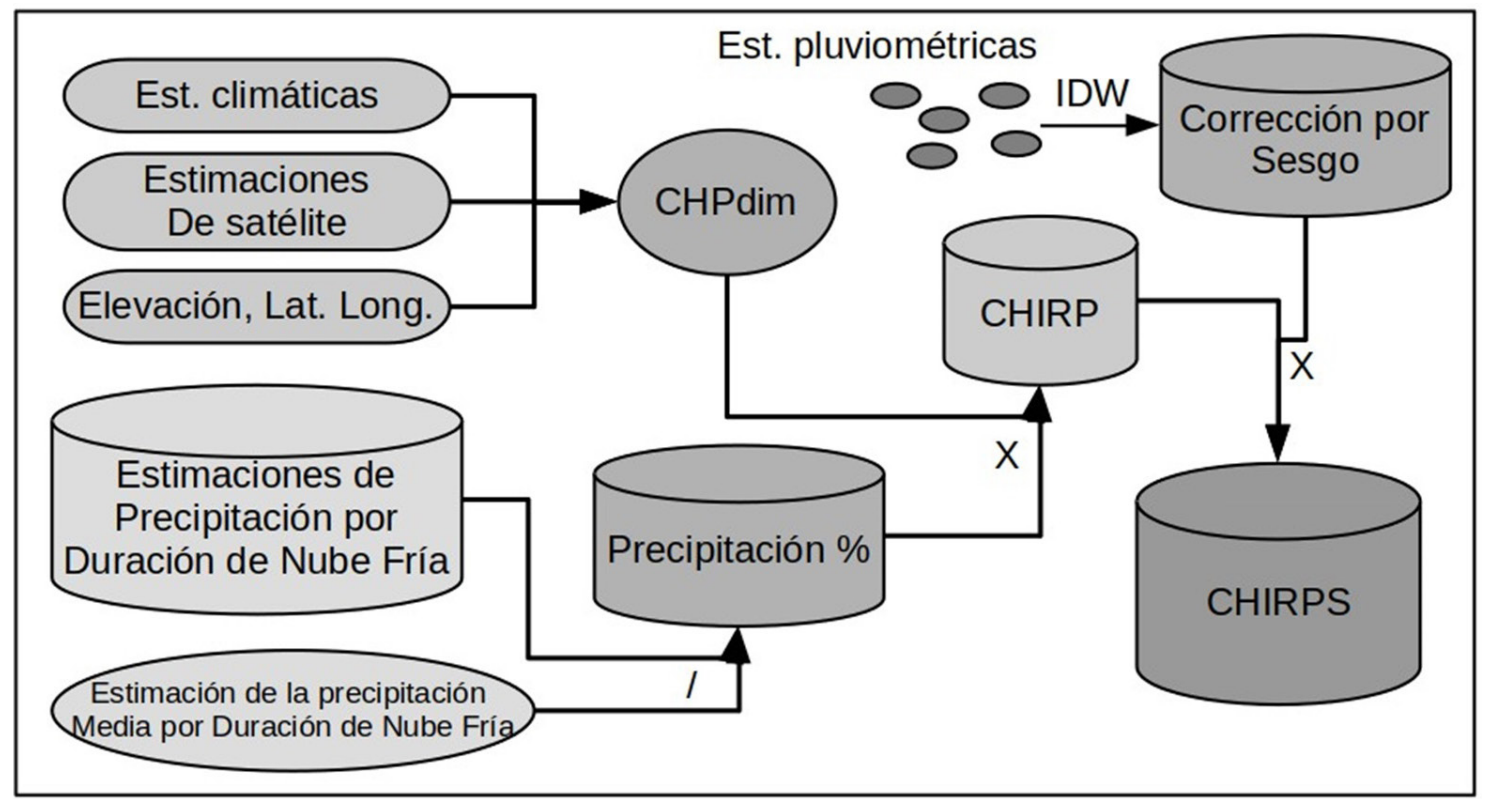

Fig. 6. Esquema de producción de CHIRPS (adaptado de Funk et al., 2015)

El algoritmo MOD16 se basa en la lógica de la ecuación de Penman-Monteith, que utiliza, como información de entrada, datos diarios de reanálisis meteorológico y dinámicas de propiedades de la vegetación de 8 días detectadas de forma remota desde el satélite MODIS. $\mathrm{El}$ algoritmo de evapotranspiración (ET) MOD16 se ejecuta a diario; temporalmente, la suma diaria es la suma de la ET de día y de noche. Verticalmente, la ET es la suma de los flujos de vapor de agua de la evaporación del suelo, la evaporación del dosel húmedo y la transpiración de la planta en la superficie seca del dosel. Se consideran: la fracción de cobertura vegetal para cuantificar cuánta radiación neta superficial se asigna entre el suelo y la vegetación; el albedo de 8 días y la radiación solar diaria en la superficie; y la temperatura del aire a partir de los datos de reanálisis meteorológicos diarios, que se utilizan para calcular la radiación neta superficial y el flujo de calor del suelo. La cobertura terrestre estimada a partir de las imágenes MODIS se usa para especificar el tipo de bioma para cada píxel, y los parámetros constantes dependientes del bioma para el algoritmo se guardan en una Tabla de Búsqueda de Propiedades del Bioma (BPLUT). El algoritmo MOD16 ha sido validado con datos de ET medida y ET estimada a partir de 232 cuencas (Mu et al., 2014). 
En la Figura 7 puede apreciarse el patrón estacional-espacial de la evapotranspiración global estimada por el algoritmo MOD16, para el periodo 2000-2010.

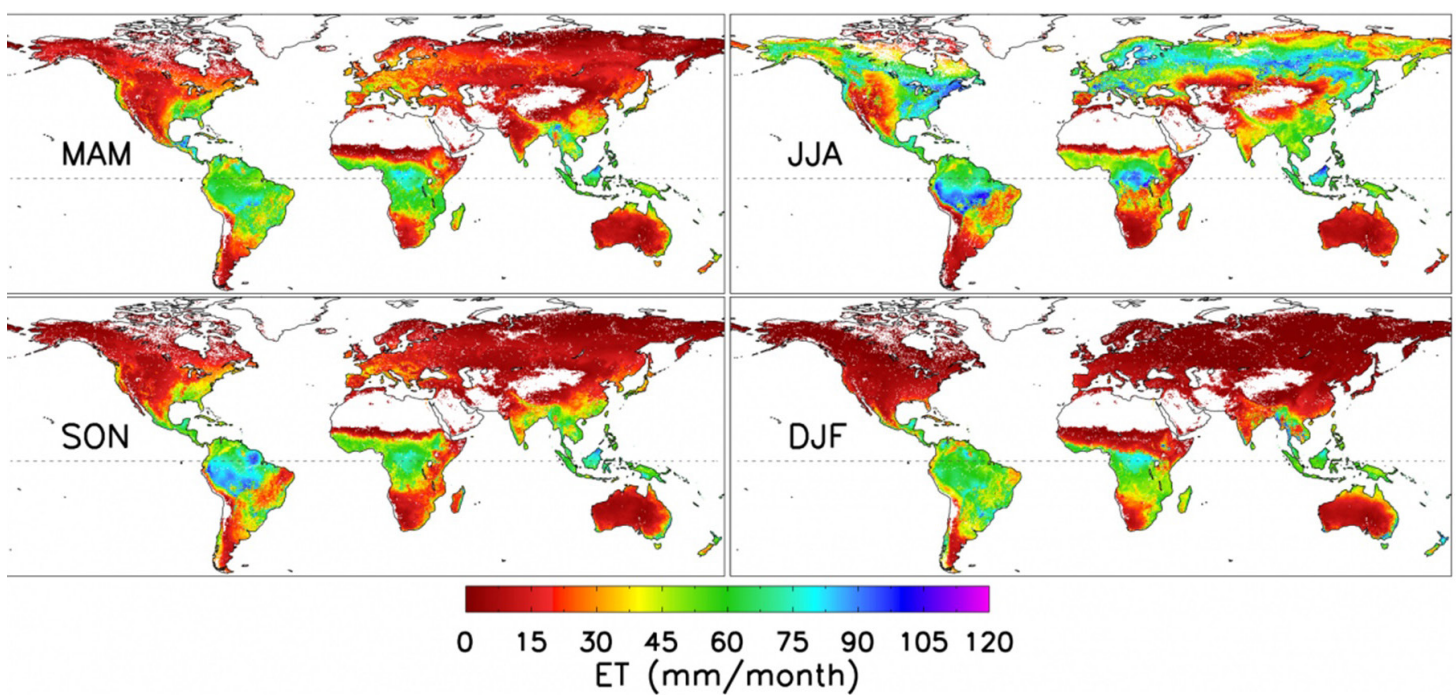

Fig. 7. patrón estacional-espacial de la ET global estimada por MOD16 (Mu et al., 2014). MAM: marzoabril-mayo; JJA: junio-julio-agosto; SON: septiembre-octubre-noviembre; DJF: diciembre-enero-febrero

\section{Modelo hidrológico}

\section{Fundamentos}

Para el desarrollo del presente trabajo se recurrió al software de modelado hidrológico TOPMODEL (Beven y Kirkby, 1979).

TOPMODEL es un modelo en el cual las dinámicas de los flujos superficial y subsuperficial se modelizan a partir de las relaciones y balances hídricos en los distintos niveles del perfil edáfico, acudiendo a planteamientos por regla general sencillos y fácilmente utilizables (Olaya, 2004). La base principal en términos de su formulación se centra en torno a su tratamiento del suelo y, muy especialmente, su utilización particular del terreno, caracterizado a partir del índice topográfico I a través de la expresión

$$
I=\ln \left(\frac{a^{\prime}}{\tan \beta}\right)
$$

donde $a$ ' es el área aportante específica -por unidad de ancho- a una celda del MDE, y tan $\beta$ la pendiente en la celda. La concepción inicial del parámetro se encamina hacia a identificación de zonas que se comporten de igual modo desde el punto de vista hidrológico, ofreciendo por tanto una idéntica respuesta en lo que respecta a la relación precipitaciónescorrentía. Sirve, por tanto, como un índice de similitud hidrológica de sumo interés para la agrupación de zonas con características homogéneas. 
Un esquema genérico de la estructura de TOPMODEL se refleja en la figura 8

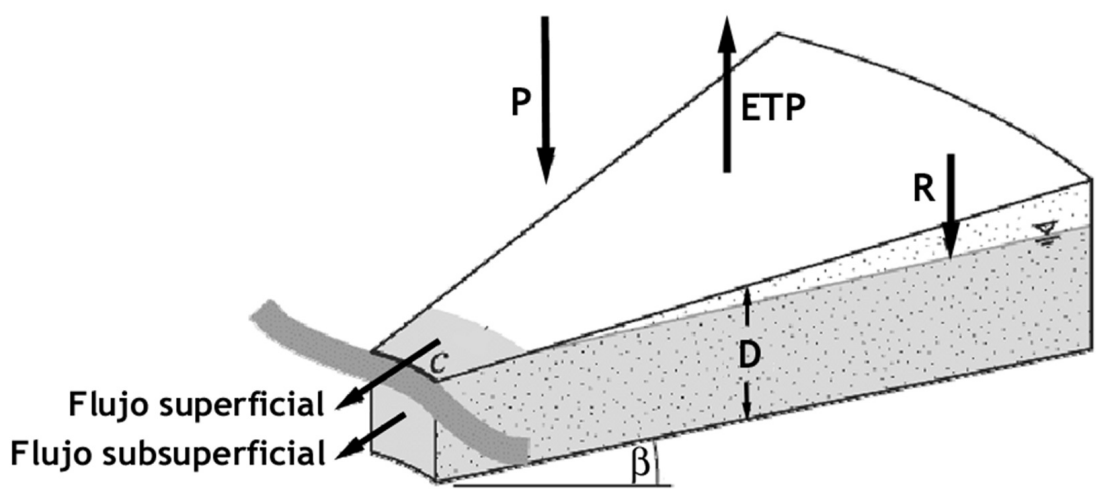

Fig. 8. Estructura conceptual del modelo TOPMODEL (Olaya, 2004)

Las hipótesis en que se fundamenta TOPMODEL pueden resumirse en las siguientes:

- El flujo subsuperficial puede ser representado por una sucesión de estados instantáneos del nivel freático

- El gradiente hidráulico del perfil saturado del suelo puede ser descrito mediante la topografía, en particular mediante la pendiente en cada punto considerado.

- La transmisividad del suelo varia de forma aproximadamente exponencial con la profundidad.

Conceptualmente, TOPMODEL se fundamenta en un esquema según el cual se compartimenta el terreno en tres zonas de almacenamiento (Figura 9):

- Zona de intercepción

- Zona no saturada

- Zona saturada

De estas tres, la evapotranspiración procede de la primera, siendo la precipitación total menos dicha evapotranspiración la cantidad que pasa a la siguiente zona (Figura 9). Para el cálculo de dicha evapotranspiración en un intervalo dado de los considerados en la modelización, se hace uso del valor de ETP que debe introducirse como parámetro en el modelo, así como de la propia cantidad del agua $S_{R}$ que se encuentre disponible en dicha zona de almacenamiento en ese intervalo. Esta cantidad ésta en función de la precipitación y del valor que tuviera en el anterior intervalo, existiendo un máximo $S R_{\text {Max }}$ que debe también introducirse como un parámetro en el modelo (Olaya, 2004). 


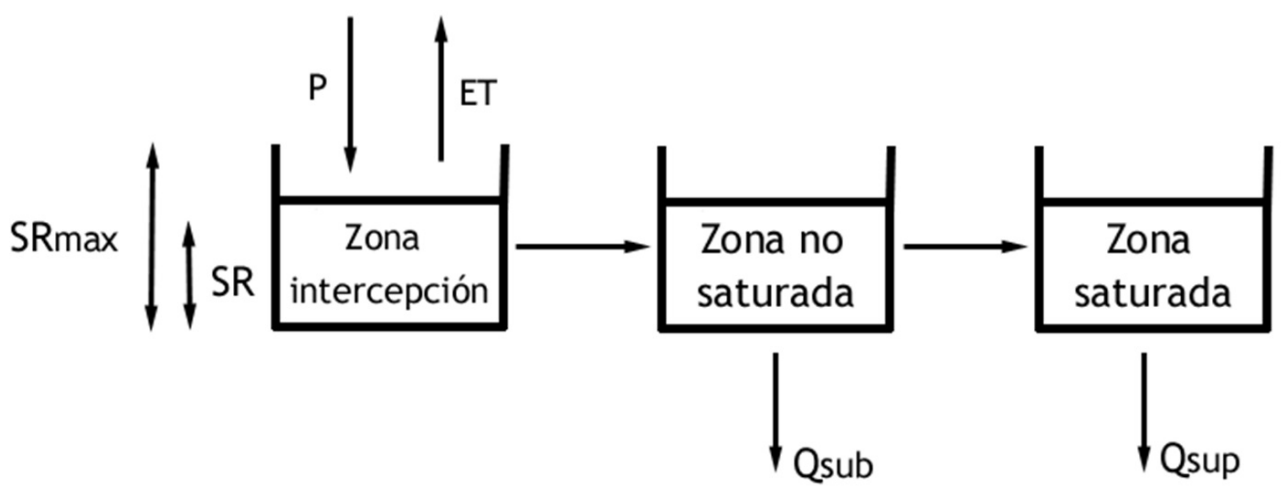

Fig. 9. Esquema de zonas y procesos en el modelo TOPMODEL (Olaya, 2004)

La ecuación fundamental en que se basa TOPMODEL, relaciona el déficit de humedad de cada celda con el índice topográfico $I$, de la forma

$$
S=\bar{S}+m[(I-\bar{I})-(\delta-\bar{\delta})]
$$

siendo m un parámetro relacionado con la disminución de la transmisividad del suelo en función de la profundidad, $S$ el déficit de humedad anterior, $I$ el índice topográfico y $\delta$ un parámetro con la expresión

$$
\delta=1 n T_{0}
$$

siendo $T_{0}$ la transmisividad del suelo. $S$, $\delta$ y $I$ representan los valores medios de la cuenca vertiente para los correspondientes parámetros.

Como puede observarse, al ser dependiente de modo exclusivo del índice topográfico como variable local, todas aquellas celdas que compartan el valor de dicho parámetro tendrán un idéntico comportamiento hidrológico. Pese a trabajar celda a celda, el modelo TOPMODEL se define como un modelo semidistribuido, ya que el cálculo de escorrentías y generación de caudales como tal no se lleva a cabo sobre el MDT y sus celdas, sino, aprovechando la similitud hidrológica de las zonas con igual valor del índice topográfico, sobre el histograma de distribución del mismo. La división de dicho histograma en una serie de clases reduce en gran medida el cálculo, pues se analizan dichas clases y se estudian los déficits de humedad en ellas, utilizando luego los porcentajes ocupados por dicha clase dentro de la cuenca para conocer las áreas totales en las que se producen los fenómenos de escorrentía y empleando éstas.

Por lo anterior, se dice con frecuencia que TOPMODEL es un modelo de área contribuyente variable ya que la fracción de la cuenca que genera escorrentía se modifica a lo largo de los intervalos que se analizan. La dimensión de este área viene condicionada por la topografía, las características del suelo y la humedad en la cuenca (Olaya, 2004). 


\section{Implementación utilizada}

Para el desarrollo del presente trabajo se utilizó la implementación realizada por Conrad (2013) de una versión simplificada de TOPMODEL a través del Sistema de Información Geográfica SAGA-GIS (Conrad et al., 2015), la cual a su vez se basa en la implementación original desarrollada por Cho (2000) en el Sistema de Información Geográfica GRASS-GIS (Cho, 2000).

Esta versión permite cálculos en subcuencas simples o múltiples, pero en base a un promedio areal de precipitaciones y evapotranspiración en toda la cuenca. Las descargas de las subcuencas se transitan a la salida de la cuenca utilizando un algoritmo de enrutamiento lineal con velocidad constante del canal principal y velocidad de tránsito en subcuencas internas. El programa requiere un mapa de distribución de I para cada subcuenca. El cálculo de exceso de infiltración se basa en el modelo de conductividad exponencial de Green-Ampt de Beven et al. (1984).

Los parámetros requeridos por el modelo, sus unidades de entrada y una breve descripción de los mismos pueden verse en la Tabla 2.

\begin{tabular}{|l|l|l|}
\hline Parámetro & Unidades & Significado \\
\hline $\mathrm{q}_{\mathrm{s} 0}$ & $\mathrm{~m} / \mathrm{h}$ & Flujo inicial subsuperficial por unidad de área \\
\hline$\delta$ & $\ln \left(\mathrm{m}^{2} / \mathrm{h}\right)$ & Media areal de la transmisividad superficial del suelo \\
\hline $\mathrm{m}$ & $(\mathrm{ad})$. & Parámetro que controla la tasa de disminución de la transmisividad \\
\hline $\mathrm{S}_{\mathrm{r} 0}$ & $(\mathrm{ad})$. & Déficit inicial de almacenamiento en la zona no saturada \\
\hline $\mathrm{S}_{\mathrm{rmáx}}$ & $(\mathrm{ad})$. & Déficit máximo de almacenamiento en la zona no saturada \\
\hline $\boldsymbol{a}$ & $\mathrm{h}$ & Gradiente hidráulico vertical efectivo \\
\hline $\mathrm{v}_{\mathrm{ch}}$ & $\mathrm{m} / \mathrm{h}$ & Velocidad de tránsito en el canal principal \\
\hline $\mathrm{v}_{\mathrm{r}}$ & $\mathrm{m} / \mathrm{h}$ & Velocidad de tránsito en canales interiores \\
\hline $\mathrm{K}_{0}$ & $\mathrm{~m} / \mathrm{h}$ & Conductividad hidráulica superfcial (Green y Ampt) \\
\hline$\Psi$ & $\mathrm{m}$ & Altura de succión capilar (Green y Ampt) \\
\hline$\Delta \theta$ & $(\mathrm{ad})$. & Cambio en el contenido de humedad en el frente húmedo (Green y Ampt) \\
\hline
\end{tabular}

Tabla 2: Parámetros de entrada para TOPMODEL en SAGA-GIS

\section{Resultados y discusión}

A partir del Modelo Digital de Elevación considerado, y a través del Sistema de Información Geográfica SAGA-GIS se delimitó la cuenca vertiente a la zona del Complejo Turístico; luego, se confeccionó el mapa del Índice Topográfico I, como se indica en la Figura 10. Pueden observarse dos zonas con altos valores de I: la cabecera de cuenca (debido a las bajas pendientes topográficas), coincidente con la zona de mayor aprovechamiento pecuario, y la zona de cierre, correspondiente al área acumulada aportante total de la cuenca; vinculadas por la red de drenaje con un efecto meramente traslatorio del escurrimiento. 


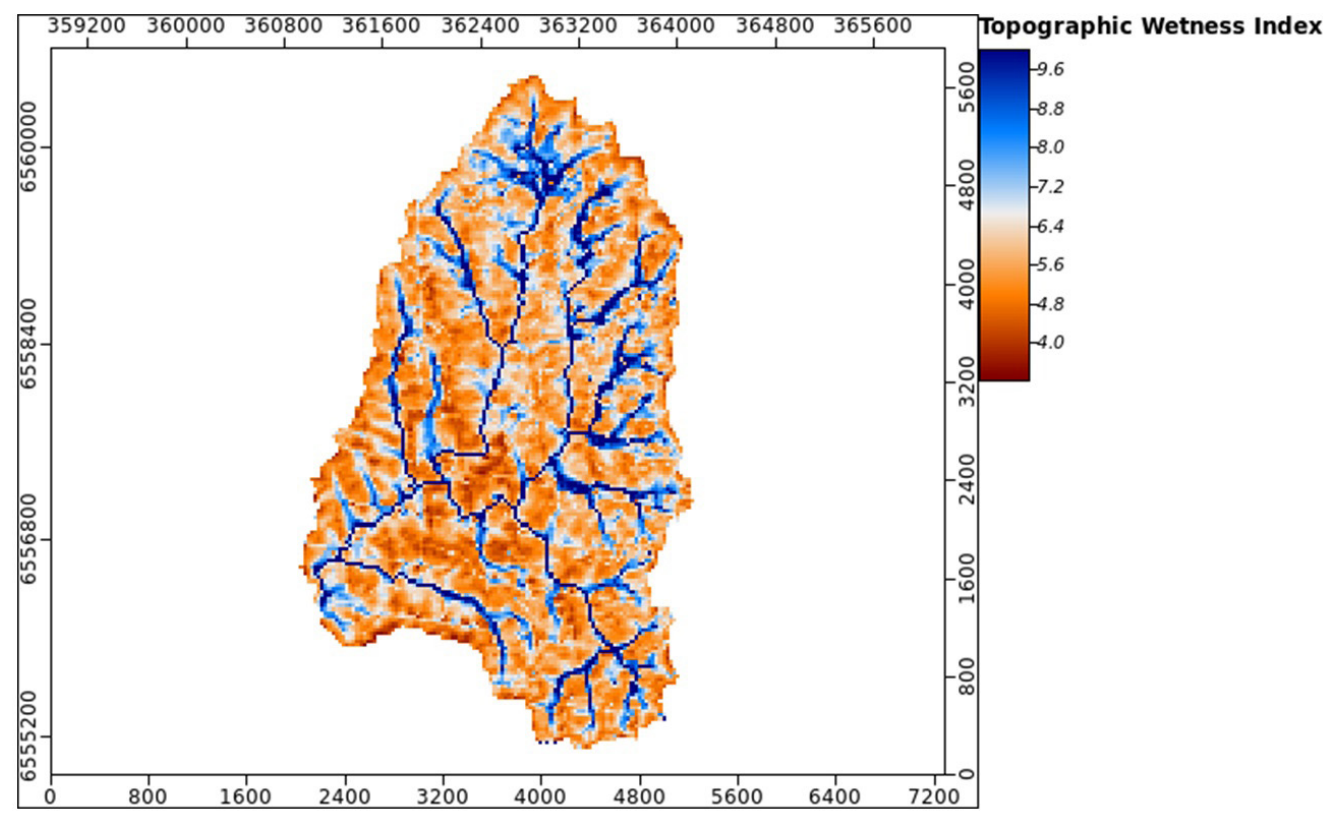

Fig. 10. Índice Topográfico de humedad del suelo

En ausencia de registros pluviométricos-hidrométricos que hubieran permitido la calibración de los parámetros del modelo, éstos fueron estimados en base a lo reportado en la bibliografía para diversas cuencas de características similares simuladas en el mundo. En particular, resulta de interés el resumen presentado por Beven (1997) de donde se seleccionaron los valores mínimos, típicos y máximos indicados en la Tabla 3.

Se simularon los 11 años hidrológicos comprendidos entre el año 2000-2001 y el 2010-2011; sin embargo, se presentan los resultados de los 10 años hidrológicos comprendidos entre el 2001-2002 y el 2010-2011, considerando al primer año como un periodo de precalentamiento del modelo (warm-up). De este modo, el modelo logra independizarse de las condiciones iniciales arbitrariamente fijadas en la simulación.

\begin{tabular}{|l|c|c|c|}
\hline Parámetro & mínimo & típico & máximo \\
\hline $\mathrm{q}_{\mathrm{s} 0}$ & 0,00004 & 0,00005 & 0,00006 \\
\hline$\delta$ & 1,0 & 2,0 & 3,0 \\
\hline $\mathrm{m}$ & 0,02 & 0,04 & 0,06 \\
\hline $\mathrm{S}_{\mathrm{r} 0}$ & 0,0020 & 0,0025 & 0,0030 \\
\hline $\mathrm{S}_{\mathrm{rmáx}}$ & 0,040 & 0,045 & 0,050 \\
\hline $\mathrm{a}$ & 50 & 55 & 60 \\
\hline $\mathrm{v}_{\mathrm{ch}}$ & 5400 & 7200 & 9000 \\
\hline $\mathrm{v}_{\mathrm{r}}$ & 3600 & 5400 & 7200 \\
\hline $\mathrm{K}_{0}$ & 0,06 & 0,12 & 0,18 \\
\hline$\Psi$ & 0,04 & 0,06 & 0,08 \\
\hline$\Delta \theta$ & 0,30 & 0,35 & 0,40 \\
\hline
\end{tabular}

Tabla 3: Parámetros de entrada para TOPMODEL en SAGA-GIS 
Se realizó un análisis de incertidumbre sobre los caudales resultados del modelado. Para ello, se tomaron los conjuntos de parámetros mínimo y máximo y se plantearon todas las combinaciones posibles entre ellos; de modo de generar $2^{11}=2048$ juegos de parámetros. Con cada juego se aplicó TOPMODEL para obtener un hidrograma de descarga de la cuenca. Con este conjunto de realizaciones se determinaron las envolventes superior e inferior, que junto con la simulación correspondiente a los parámetros típicos, dieron lugar al hidrograma de descarga presentado en las Figuras 11 (en escala lineal, donde se destacan los caudales pico) y 12 (en escala logarítmica, donde se aprecian los caudales de estiaje).

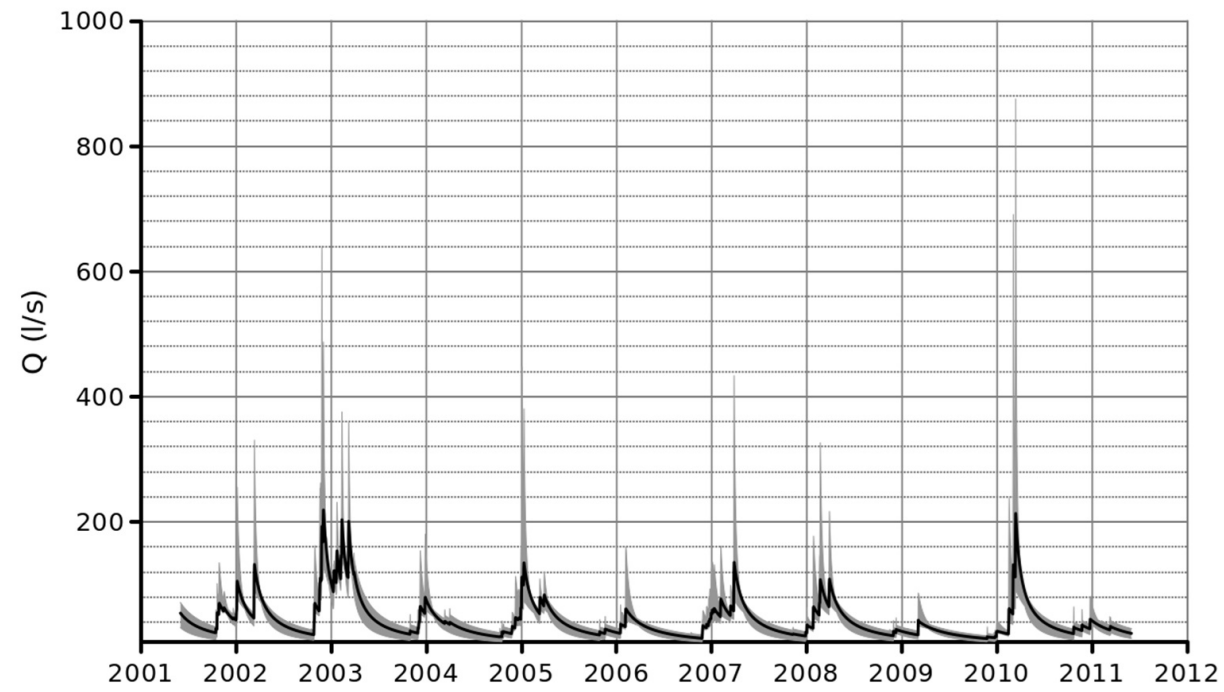

Fig. 11. Hidrograma resultado. La línea negra continua representa el escenario típico, mientras que la banda gris el intervalo de resultados posibles entre los escenarios mínimo y máximo.

A modo de ejemplo, se presentan en la Figura 13 los resultados de detalle para dos años hidrológicos: 2005-2006 y 2007-2008, en conjunto con la precipitación diaria y la evapotranspiración diaria considerada en la simulación.

El análisis de la serie de caudales simulados permitió obtener, para el periodo reportado, un caudal medio (módulo) de 43 1/s, en un intervalo comprendido entre 30 y 59 1/s (para las envolventes de mínima y máxima).; es decir, una incerteza de $(-31 \% ;+39 \%)$.

En la Figura 14 se presenta la curva de caudales clasificados en base a los resultados obtenidos, para el conjunto de parámetros típico (Tabla 2) y para los 10 años hidrológicos simulados y reportados. Puede verse la amplia dispersión en los caudales pico. De esta curva se obtienen los valores característicos indicados en la Tabla 4. El caudal mediano (de 35,2 1/s) presenta una variabilidad, para el periodo simulado, de $(-39 \% ;+81 \%)$. 


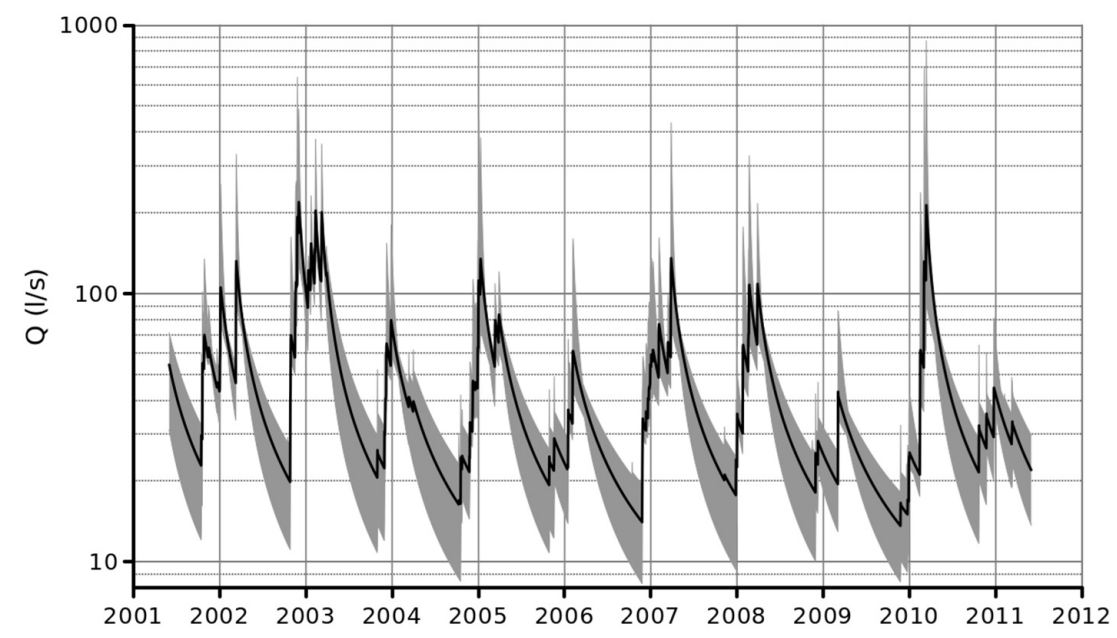

Fig. 12. Igual que la figura anterior, pero en escala logarítmica
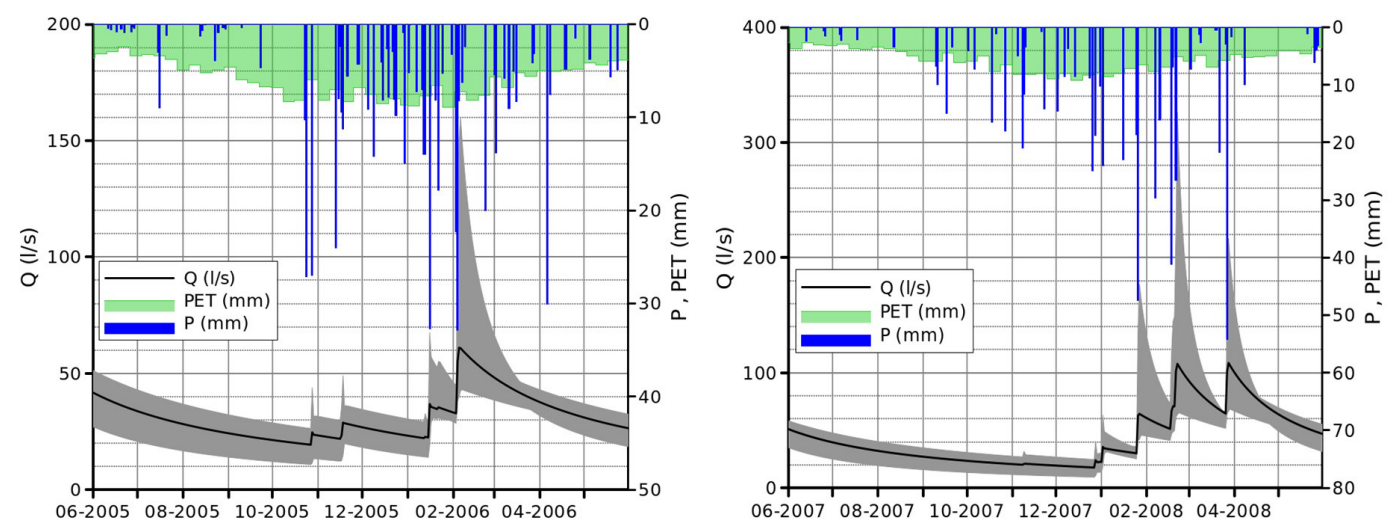

Fig. 13. Hidrogramas de descarga simulados para los años hidrológicos 2005-2006 (izquierda) y 2007-2008 (derecha). La línea negra continua representa el escenario típico, mientras que la banda gris el intervalo de resultados posibles entre los escenarios mínimo y máximo. Se superponen la precipitación (P) y la evapotranspiración (PET) diaria

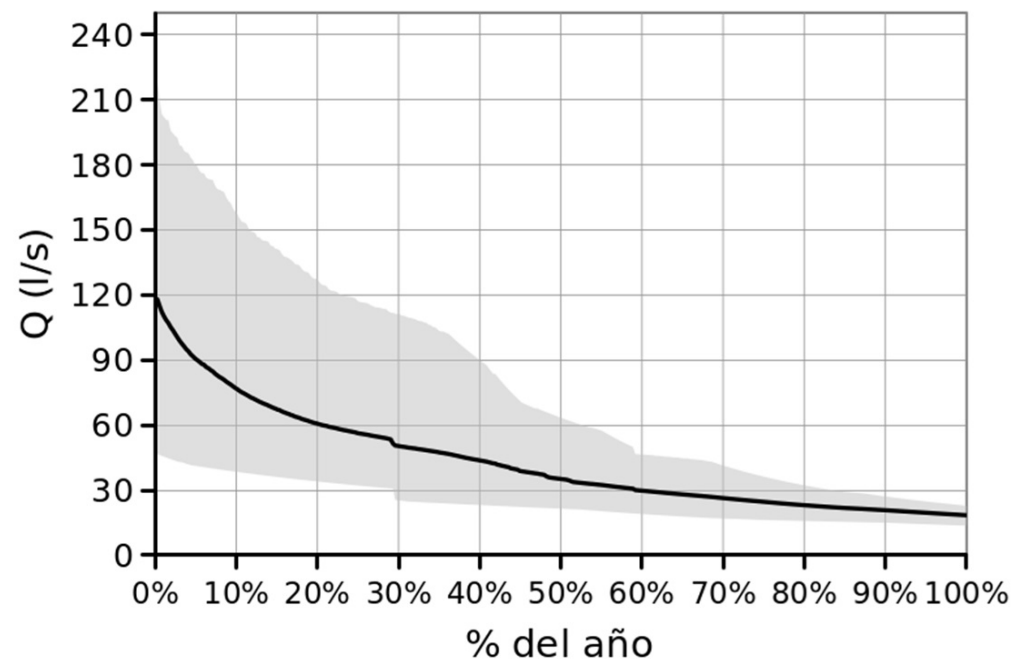

Fig. 14. Curva de caudales clasificados, obtenida a partir de las simulaciones. La línea negra continua representa los valores medios; la banda gris el intervalo de resultados 


\begin{tabular}{|l|l|l|l|}
\hline Permanencia & mínimo & medio & máximo \\
\hline $95 \%$ & 14,3 & 19,6 & 24,8 \\
\hline $50 \%$ & 21,5 & 35,2 & 63,6 \\
\hline $5 \%$ & 41,2 & 90,5 & 180,0 \\
\hline
\end{tabular}

Tabla 4: Caudales (en l/s) obtenidos a partir de la curva de caudales clasificados

Los caudales medios diarios obtenidos (para el escenario de parámetros típico) fueron procesados para obtener la serie de caudales medios mensuales simulados, representados en la Figura 15. Puede observarse la marcada estacionalidad en la respuesta hidrológica de la cuenca.

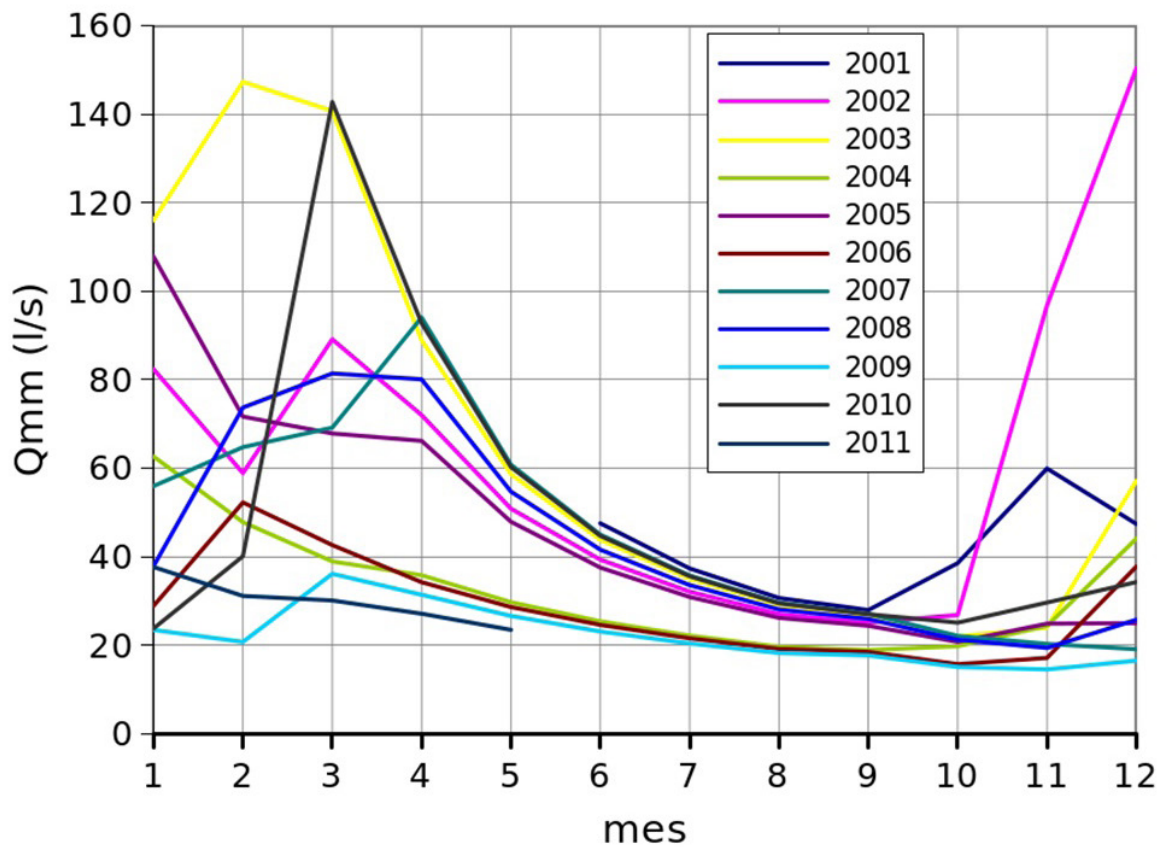

Fig. 15. Caudales medios mensuales (en l/s) para los años simulados

En base a estos resultados agregados mensuales, fue posible realizar un análisis de la severidad de las sequías en la cuenca. Para ello, se recurrió a la estimación del Índice de Sequía Fluvial (Streamflow Drought Index -SDI-) (Tigkas et al., 2015)

$$
S D I_{i, k}=\frac{V_{i, k}-\overline{V_{k}}}{s_{k}}, i=1,2, \ldots . \quad k=1,2,3,4
$$

en el cual $V_{i, k}$ es el volumen de escorrentía acumulado para el año hidrológico $i$ y el periodo de referencia $k(k=1$ para junio-agosto, $k=2$ para septiembre-noviembre, $k=3$ para diciembre-febrero y $k=4$ para marzo-mayo), dados por 


$$
V_{i, k}=\sum_{j=1}^{3 k} Q_{i, j} \quad, i=1,2, \ldots, \quad j=1,2, \ldots, 12 \quad k=1,2,3,4
$$

y $V_{k}$ y $s_{k}$ son, respectivamente, la media y el desvío estándar de los volúmenes de escorrentía acumulados. Los resultados del SDI se muestran en la Figura 16, junto con los límites que caracterizan los estados de sequía (Tigkas et al., 2015): leve ( $0>$ SDI $>-1)$, moderado $(-1>$ SDI $>-1,5)$, severo $(-1,5>$ SDI $>-2)$ y extremo $(-2>\mathrm{SDI})$.

Como puede observarse en la Figura 16, el periodo de análisis presenta tres intervalos completos de sequía, en los años hidrológicos 2003-2004 (de 9 meses de extensión), 20052006 (de 21 meses de duración) y 2008-2009 (de 21 meses de duración), más dos trimestres al final de periodo simulado. Sin embargo, sólo seis trimestres (uno en el primer intervalo, dos en el segundo y tres en el tercero) presentan una caracterización de sequía moderada, y uno (invierno de 2009) correspondiente a una sequía severa (SDI $=-1,53$ ), quedando los restantes periodos clasificados como sequía leve, y no observándose periodos de sequía extrema. Esto se correspondería con la descripción cualitativa de la relativa abundancia hídrica de la cuenca de Vaquerías (en relación incluso a cuencas vecinas). También se observa un periodo continuo de once trimestres (años hidrológicos 2001-2003) con valores de SDI > 0, es decir, ausencia de sequía, en correspondencia con el ciclo húmedo observado en la región central del país.

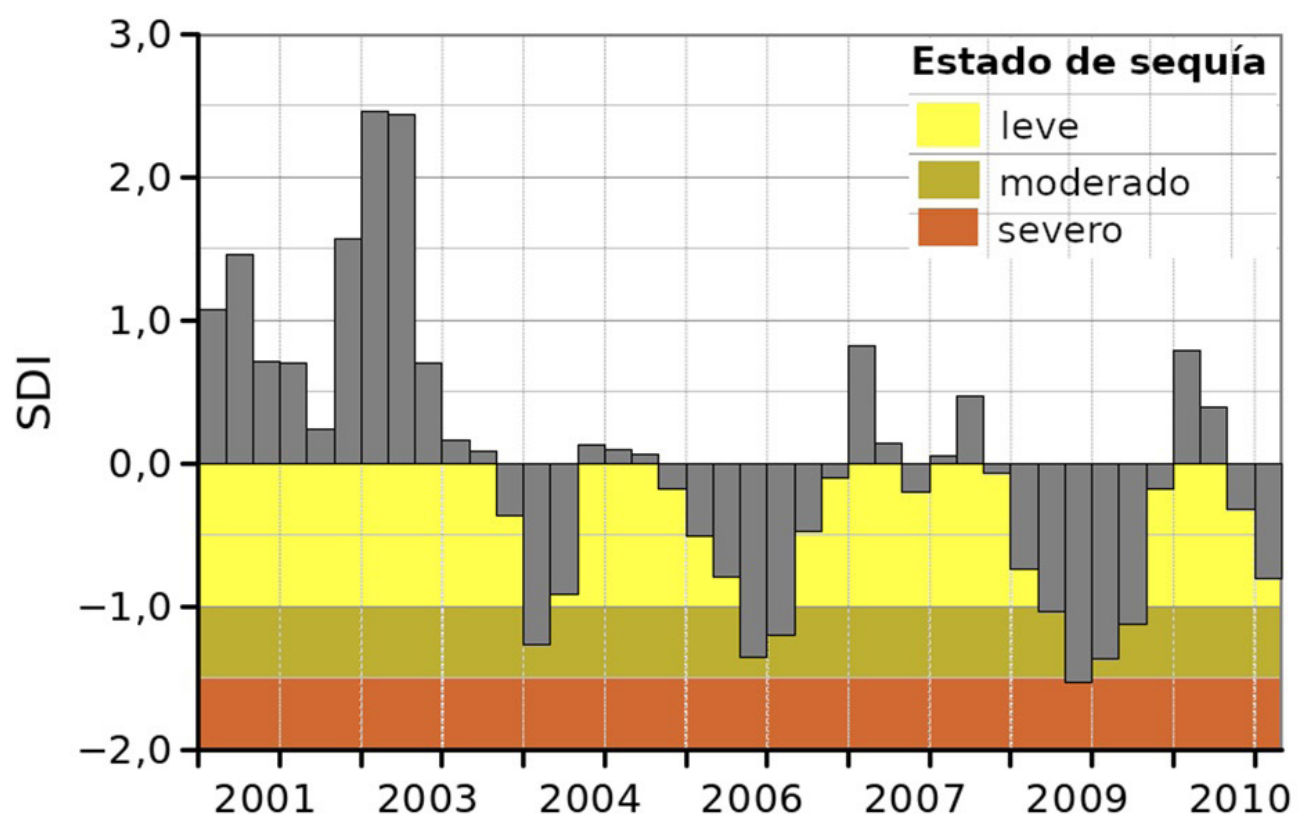

Fig. 16. Índice de sequía fluvial (SDI) basado en los resultados agregados por trimestre. Las bandas de color representan los estados de sequía

Finalmente, se realizó un análisis de extremos hidrológicos sobre las series de caudales medios diarios máximos anuales, a través del programa CumFreq (Oosterbaan, 2019). 
Nuevamente, en análisis se realizó en base a los resultados obtenidos, para el conjunto de parámetros típico. Se observó que la distribución GEV (distribución de Valores Extremos Generalizada) resultó la de mejor ajuste:

$$
F_{c}=e^{-\left(1+K \frac{(Q-A)}{B}\right)^{-1 / K}}
$$

donde $F_{c}$ es la frecuencia relativa acumulada, $Q$ son los caudales máximos, y $A, B$ y $K$ son los parámetros de la distribución.

La Figura 17 representa la distribución de probabilidades de no excedencia (expresada como periodo de retorno) en función del caudal máximo anual. En la Tabla 5 se presentan, a título de ejemplo, algunos valores de referencia.

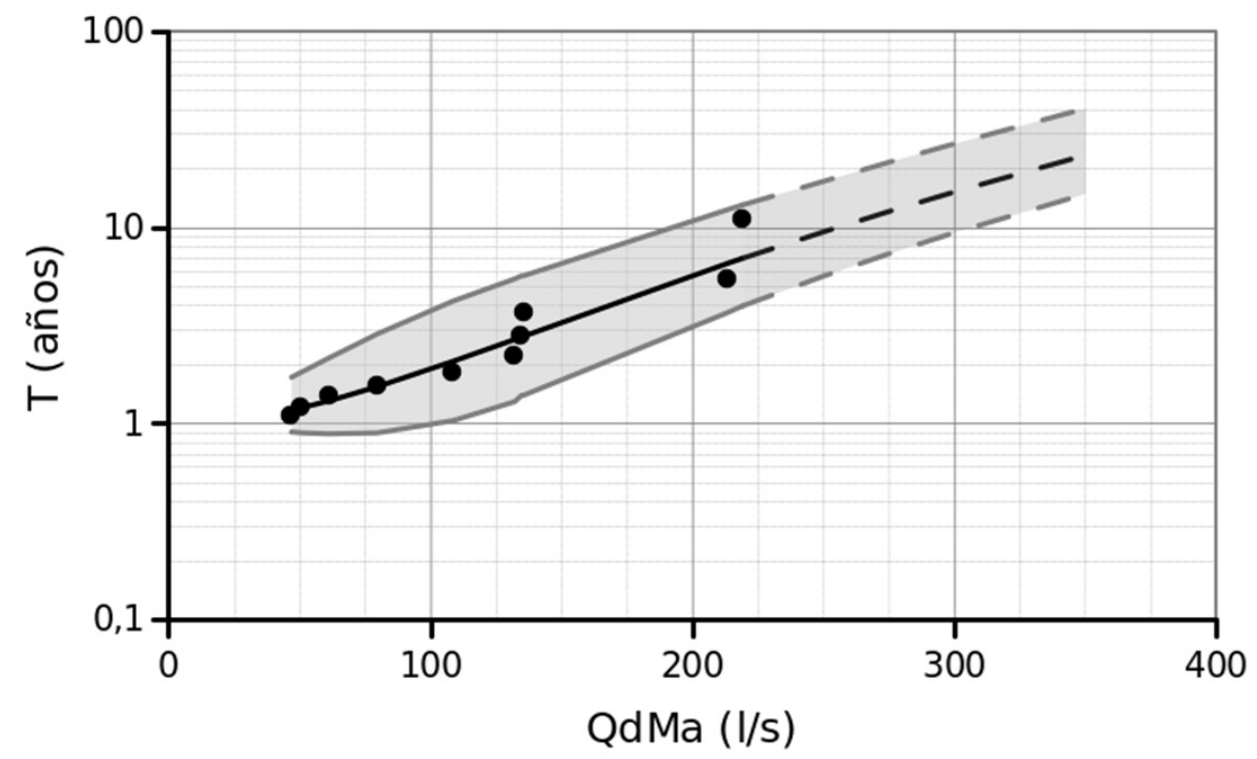

Fig. 17. Distribución de periodos de retorno, en función de los caudales diarios máximos anuales $(\mathrm{QdMa})$. Los puntos representan los resultados de la serie simulada; la línea continua, el modelo estadístico de la distribución GEV ajustada ; la banda gris, los límites de $90 \%$ de confianza. Las líneas de trazos corresponden a la extrapolación

\begin{tabular}{|c|c|}
\hline T (años) & Q (I/s) \\
\hline 5 & 187 \\
\hline 10 & 255 \\
\hline 15 & 298 \\
\hline 20 & 331 \\
\hline 25 & 358 \\
\hline
\end{tabular}

Tabla 5: Caudales diarios en función del periodo de retorno 


\section{Conclusiones}

Ante la necesidad de lograr una descripción cuantitativa de la hidrología de la cuenca del arroyo Vaquerías, como punto de partida de un Plan de Manejo para la Reserva, y ante la total ausencia de mediciones locales de calidad y extensión necesarias, se recurrió al modelado hidrológico. En el contexto de una cuenca no instrumentada, el modelado hidrológico puede brindar, con sus limitaciones e incertidumbres, cuantificaciones que permiten una mejor caracterización del recurso hídrico.

TOPMODEL presenta dos ventajas singulares: a pesar de ser un modelo semidistribuido (que considera con suficiente precisión la influencia topográfica en la respuesta hidrológica de la cuenca), presenta una alta eficiencia computacional, en particular cuando solo se requieren resultados agregados; y permite considerar, en la respuesta hidrológica de la cuenca, la contribución tanto del flujo superficial como subterráneo.

El uso combinado de TOPMODEL, los Modelos Digitales de Elevaciones, los Datos de Precipitación Derivados de Satélites (DPDS) y otra información hidrológica requerida como la evapotranspiración, también procedente del sensoramiento remoto, eficientemente adquirida y preprocesada a través de Google Earth Engine, en forma integrada a través de Sistemas de Información Geográfica, permite al modelador obtener estimaciones razonables en forma rápida y eficiente.

La ejecución iterativa de TOPMODEL, junto con la definición de sus parámetros a través de intervalos de valores (en lugar de cantidades determinísticas), permite obtener resultados expresados como intervalos de confianza.

El uso de un periodo de precalentamiento (warm-up) permitió independizar los resultados obtenidos de las inciertas condiciones iniciales, necesarias para llevar a cabo la simulación.

A partir de los hidrogramas generados para un periodo de 10 años hidrológicos, fue posible describir la distribución estadística de caudales medios (a través de una curva de caudales clasificados), la caracterización de los periodos de sequía, y la estimación de los caudales extremos, en base al periodo de retorno.

Se considera que los resultados aquí presentados permiten describir las características hidrológicas de la cuenca del arroyo Vaquerías, en ausencia de registros; sin embargo, no debe perderse de vista que "ninguna metodología podrá aumentar los datos existentes, sin embargo permitirá extraer mejor la información ya existente” (Tucci, 1998).

Una mejor descripción de la hidrología de la cuenca del arroyo Vaquerías requerirá, como exigencia inmediata, la medición y monitoreo de las variables hidrológicas e hidrometeorológicas necesarias.

\section{Agradecimientos}

El autor agradece a la Secretaría de Ciencia y Tecnología de la Universidad Tecnológica Nacional por la financiación del proyecto MSUTICO0007675TC, en el que se enmarca el presente trabajo. 


\section{Referencias}

Abril, E. (2012). Geología y geomorfología de Vaquerías. pp. 27-37. En: Kufner, Maura (Coord.) (2012). Reserva Natural de Vaquerías: patrimonio natural y sociocultural: planificación sustentable de la reserva y su entorno regional. 332 p. ISBN 978-950-33-1001-4. Editorial de la Universidad Nacional de Córdoba.

Abril, E. y Zanvettor, R. (2012). Clima en la región de Vaquerías. pp. 21-25. En: Kufner, Maura (Coord.) (2012). Reserva Natural de Vaquerias: patrimonio natural y sociocultural: planificación sustentable de la reserva y su entorno regional. 332 p. ISBN 978-950-33-1001-4. Editorial de la Universidad Nacional de Córdoba.

Beven, K. (1997). “TOPMODEL: a critique”. Hydrological processes, 11(9), 1069-1085.

Beven, K. J., y Kirkby, M. J. (1979). "A physically based, variable contributing area model of basin hydrology". Hydrological Sciences Journal, 24(1), 43-69.

Beven, K., Kirkby, M.J., Schofield, N., Tagg, A.F. (1984). “Testing a physically-based flood forecasting model (TOPMODEL) for threee U.K. catchments”. Journal of Hydrology, H.69, S.119-143.

Cejas, G., y Sacchi, G. (2012). Suelos de Vaquerias. pp. 39-55. En: Kufner, Maura (Coord.) (2012). Reserva Natural de Vaquerias: patrimonio natural y sociocultural: planificación sustentable de la reserva y su entorno regional. 332 p. ISBN 978-950-33-1001-4. Editorial de la Universidad Nacional de Córdoba.

Cho, H., (2000). "GIS Hydrological Modeling System by Using Programming Interface of GRASS” (Master's Thesis). Department of Civil Engineering, Kyungpook National University, Korea.

Conrad, O. (2013). System for Automated Geoscientific Analyses Module Library: sim_hydrology, topmodel. Cpp. < www.saga-gis.org/saga_tool_doc/2.1.3/sim_hydrology_2.html>

Conrad, O., Bechtel, B., Bock, M., Dietrich, H., Fischer, E., Gerlitz, L., Wehberg, J., Wichmann, V., y Boehner, J. (2015). "System for Automated Geoscientific Analyses (SAGA) v. 2.1.4”. Geosciences Model Development., 8, 1991-2007, doi:10.5194/gmd-8-1991-2015.

Farr, T.G., Rosen, P.A., Caro, E., Crippen, R., Duren, R., Hensley, S., Kobrick, M., Paller, M., Rodriguez, E., Roth, L., Seal, D., Shaffer, S., Shimada, J., Umland, J., Werner, M., Oskin, M., Burbank, D., y Alsdorf, D.E. (2007). “The Shuttle Radar Topography Mission”. Reviews of Geophysics, v. 45, no. 2, RG2004, <https://doi.org/10.1029/2005RG000183>.

Funk, C., Peterson, P., Landsfeld. M., Pedreros. D., Verdin, J., Shukla, S., Husak, G., Rowland, J., Harrison, L., Hoell, A. y Michaelsen, J. (2015). "The climate hazards infrared precipitation with stations-a new environmental record for monitoring extremes". Scientific Data 2, 150066. doi:10.1038/sdata.2015.66.

Gorelick, N., Hancher, M., Dixon, M., Ilyushchenko, S., Thau, D., y Moore, R. (2017). Google Earth Engine: Planetary-scale geospatial analysis for everyone. Remote Sensing of Environ- 
ment. 202, 18-27, ISSN 0034-4257, DOI: <https://doi.org/10.1016/j.rse.2017.06.031>

Kufner, Maura (Coord.) (2012). Reserva Natural de Vaquerias: patrimonio natural y sociocultural: planificación sustentable de la reserva y su entorno regional. 332 p. ISBN 978-950-33-1001-4. Editorial de la Universidad Nacional de Córdoba.

Olaya, V. (2004). Hidrología Computacional y Modelos Digitales del Terreno:Teoría, práctica y filosofía de una nueva forma de análisis hidrológico. <http://heart.sf.net/textos>

Oosterbaan, R. J. (2019). "Software for Generalized and Composite Probability Distributions". International Journal of Mathematical and Computational Methods, 4, 1-9.

QGIS Development Team. (2020). “QGIS Geographic Information System”. Open Source Geospatial Foundation Project. <https://www.qgis.org/es/site/index.html>

Mu, Q., Zhao, M., Running, S. y Numerical Terradynamic Simulation Group (2014) "MODIS Global Terrestrial Evapotranspiration (ET) Product MOD16A2 Collection 5”. College of Forestry and Conservation, The University of Montana.

Rodriguez, E., Morris, C. y Belz, J. (2006). "A global assessment of the SRTM performance". Photogrammetric Engineering \& Remote Sensing, 72(3), 249-260.

Tigkas, D., Vangelis, H., y Tsakiris, G. (2015). "DrinC: a software for drought analysis based on drought indices”. Earth Science Informatics, 8(3), 697-709.

Toledo, J. y Nóbile, R. Flora de la Reserva Natural de Vaquerías. pp. 77-97. En: Kufner, Maura (Coord.) (2012). Reserva Natural de Vaquerías: patrimonio natural y sociocultural: planificación sustentable de la reserva y su entorno regional. 332 p. ISBN 978-950-33-1001-4. Editorial de la Universidad Nacional de Córdoba.

Tucci, C.E.M. (1998) Modelos Hidrológicos. Editora da Universidade, UFRGS / Asociação Brasileira de Recursos Hídricos.

Weber, J. (2012). Cuenca Hidrica del arroyo Vaquerías. Hidrología Superficial. pp. 57-67. En: Kufner, Maura (Coord.) (2012). Reserva Natural de Vaquerias: patrimonio natural y sociocultural: planificación sustentable de la reserva y su entorno regional. 332 p. ISBN 978-950-33-1001-4. Editorial de la Universidad Nacional de Córdoba. 